\title{
Effect of Topical Moxifloxacin on the Bacterial Flora of the Ocular Surface following Cataract Surgery: A Randomized, Single-Masked Clinical Trial
}

\author{
Erick Mendoza-Schuster*, Guadalupe Cervantes-Coste, Virginia Vanzzini and Cecilio \\ Velasco-BaronaD
}

Asociación Para Evitar la Ceguera en México I.A.P, Hospital "Dr. Luis Sánchez Bulnes", México City, México

*Corresponding author: Erick Mendoza-Schuster, MD, Asociación Para Evitar la Ceguera en México I.A.P, Hospital "Dr. Luis Sánchez Bulnes", General Cano 44 PH-B, México City, 11850, México, Tel: +(525)-26146665, E-mail: erickms@me.com

\begin{abstract}
Objective: To determine the efficacy of topical $0.5 \%$ moxifloxacin ophthalmic solution in reducing conjunctival flora when administered for 3 days versus 1 hour prior to surgery.

Methods: This was a randomized, single-masked, comparative, longitudinal, single-center study. Sixty eyes of 60 patients scheduled for cataract surgery were randomized to receive either 1 drop of moxifloxacin 4 times daily for 3 days prior to surgery or 1 drop every 15 minutes for 1 hour prior to surgery. The non-surgical eye of each patient served as the no-treatment control. Conjunctival cultures were obtained from both eyes at baseline $\left(\mathrm{t}_{0}\right)$ and 1 hour after the last dose of treatment $\left(\mathrm{t}_{1}\right)$.

Results: There was no statistically significant difference ( $p$ $=0.54$ ) in the percent of culture-positive eyes between the 3-day and 1-hour groups at baseline; however, the difference was statistically significant $(p=0.035)$ in favor of the 3-day group at $t_{1}$. The mean number of colony forming units (CFU) was significantly lower at $t_{1}$ compared to $t_{0}$ in the 3 -day group $(p=0.04)$, but not in the 1-hour group $(p=0.73)$. At $t_{1}$, eyes in the 3-day group showed statistically significant reduction in the percent of culture-positive eyes $(p=0.019)$ and the mean number of CFU ( $p=0.002$ ) for $S$. epidermidis; the most frequently isolated organism from swab samples at $t_{0}$ and $t_{1}$. No treatment-related adverse events were reported.

Conclusion: The 3-day prophylactic regimen with $0.5 \%$ moxifloxacin ophthalmic solution resulted in statistically significantly fewer positive conjunctival cultures and fewer CFU than the 1-hour regimen, suggesting 3-day regimen would prevent postoperative endophthalmitis.
\end{abstract}

\section{Keywords}

Cataract, Prophylaxis, Moxifloxacin, Endophthalmitis

\section{Introduction}

Postoperative bacterial endophthalmitis is one of the most devastating complications following cataract surgery. Fortunately, postoperative endophthalmitis is a rare condition, with reported rates ranging between $0.08 \%$ and $0.26 \%$ [1-6]; however, when taking into account the millions of people who have cataract surgery every year, postoperative endophthalmitis becomes a significant public health issue [7]. Despite the advances in intraocular surgery techniques and technology, and the use of chemo-prophylactic agents, the incidence of postoperative endophthalmitis continues to rise $[8,9]$. In the United States, the incidence of postoperative endophthalmitis has increased from 1.79 cases per 1000 in 1994 to 2.47 cases per 1000 in 2001, an approximately $28 \%$ increase over this 7 -year period [8,9]. This upward trend in endophthalmitis frequency coincides temporally with the development of sutureless clear corneal incisions, but no definitive conclusions regarding its cause can yet be made [8].

The most common sources of bacterial endophthalmitis are the eyelids and conjunctiva [10]. In theory, reducing the bacteria load from the ocular surface prior to surgery should result in lower anterior chamber contamination during intraocular surgery [10-16]. Techniques to reduce pathogens from the ocular surface include preparation of the skin and conjunctiva with povidone-iodine. It has been demonstrated that using these measures reduces pathogens from the ocular surface

Citation: Mendoza-Schuster E, Cervantes-Coste G, Vanzzini V, Velasco-BaronaD C (2018) Effect of Topical Moxifloxacin on the Bacterial Flora of the Ocular Surface following Cataract Surgery: A Randomized, Single-Masked Clinical Trial. Int J Ophthalmol Clin Res 5:088. doi.org/10.23937/2378-346X/1410088

Accepted: June 23, 2018: Published: June 25, 2018

Copyright: (C) 2018 Mendoza-Schuster E, et al. This is an open-access article distributed under the terms of the Creative Commons Attribution License, which permits unrestricted use, distribution, and reproduction in any medium, provided the original author and source are credited. 
[16-18]. Additionally, the application of antibiotics has proved effective in reducing the microbial load on the eyelids and conjunctiva in asymptomatic patients [912]. The use of intracameral antibiotics also has yielded good results $[13,14]$. Although it is impossible to completely eliminate bacterial flora from the ocular surface, even by using antibiotics and antiseptics, prophylactic use of antibiotics has been shown to reduce the risk of postoperative infection $[12,19]$.

Approximately $80 \%$ of patients have positive cultures prior to surgery, with coagulase-negative Staphylococcus bacteria being the most frequently cultured pathogen [11]. The use of a topical antibiotic agent combined with povidone-iodine immediately before surgery is the most frequently practiced method to reduce the bacterial flora on the conjunctival surface [20]. The optimum preoperative antibiotic regimen, however, has not been defined due to the significant variations among surgeons with respect to the antibiotic choice and administration regimen. Ta, et al. [21]. provide evidence that the administration of a topical antibiotic agent on the same day of surgery would not allow for sufficient exposure time to reduce bacterial count, and that the administration of topical antibiotic for 2 or 3 days prior to surgery would be more effective in eliminating bacteria from the ocular surface than the administration of the antibiotic on the day of surgery $[21,22]$. Other surgeons believe that the use of antibiotic agents on the day of surgery is sufficient, [20,23-25] yet others use a combination of these regimens $[26,27]$.

Although the risk of postoperative ocular infection is low, prophylactic topical antibiotics are used routinely after ocular surgery to prevent postoperative infection, especially in cases where the risk of infection might be high or the consequences of the infection, such as in endophthalmitis, might be devastating. Fluoroquinolones, especially fourth-generation fluoroquinolones, have been effective against many of the bacterial pathogens that are responsible for postoperative infections following intraocular procedures, such as cataract, glaucoma, and corneal surgeries. Fluoroquinolones are bactericidal agents with enzyme inhibitory activity against bacterial DNA gyrase and topoisomerase IV [28,29]. Fourth-generation fluoroquinolones - $0.5 \%$ moxifloxacin hydrochloride ophthalmic solution (Vigamox ${ }^{\circledR}$, Alcon Laboratories Inc., Fort Worth, TX, USA) and $0.3 \%$ gatifloxacin ophthalmic solution (Zymar ${ }^{\circledR}$, Allergan Inc., Irvine, CA, USA) - are effective against Gram-positive organisms, including S. aureus and S. epidermidis, while maintaining coverage against Gram-negative organisms that is comparable to the earlier-generation fluoroquinolones. Selection of the most appropriate antibiotic generally is based on considerations such as the spectrum of microbial coverage, bioavailability, ocular tolerability, and dosing regimen. Several clinical studies have demonstrated the superior potency [30], penetrability [31], and safety $[14,32]$ of $0.5 \%$ moxifloxacin.
The purpose of this study was to compare the efficacy of $0.5 \%$ moxifloxacin hydrochloride ophthalmic solution in reducing the microbial load from the ocular surface when administered for 3 days versus 1 hour prior to cataract surgery.

\section{Patients and Methods}

\section{Study design}

This was a prospective, randomized, single-masked, comparative, and longitudinal, single-center study conducted at the Asociación Para Evitar la Ceguera en México, IAP Hospital "Dr. Luis Sánchez Bulnes", Anterior Segment Department. The study and patients' consents were approved by the Ethics and Research Committee of the institution.

\section{Patients}

Sixty patients (120 eyes), regardless of age or gender, who were scheduled for cataract surgery and met the inclusion/exclusion criteria were included in the study from September 2006 to January 2007. The inclusion criteria were absence of active ocular infection and submission of informed consent. Patients taking topical and systemic medications were not excluded from the study, except for those taking topical ocular or systemic antibiotics for active ocular infection. Other exclusion criteria included diabetes with evidence of retinopathy, corneal endothelial disease, glaucoma, maculopathy, media opacities, uveitis, ocular trauma, ocular anomalies, presence of immunosuppressive disorder(s) or current immunosuppressive therapy, and/or knowledge or suspicion of allergy or hypersensitivity to any component of the study medication.

\section{Dosing and sample collections}

At baseline $\left(t_{0}\right)$, patients were randomized $1: 1$ into 3-day and 1-hour groups, and conjunctival cultures were obtained from all 120 eyes by a research technician from the hospital's microbiology laboratory. Patients in the 3-day group were instructed by the investigator to instill 1 drop of $0.5 \%$ moxifloxacin in the surgical eye 4 times a day for 3 days prior to surgery (a total of 12 drops), during this time, patients in the 1-hour group did not apply any topical antibiotics to either eye. On the day of surgery, patients in the 1 -hour group received 1 drop of $0.5 \%$ moxifloxacin in the surgical eye, instilled by the study coordinator, every 15 minutes for one hour prior to surgery (a total of 4 drops). The non-surgical (contralateral) eye did not receive any moxifloxacin antibiotics and was considered the no-treatment control. One hour after the last dose of each schedule, another conjunctival culture was obtained to determine the amount of bacterial flora present $\left(t_{1}\right)$.

A sterile calcium alginate swab with an aluminum shaft (Puritan Medical Products Co. LLC, Guilford, ME, USA) was used to obtain bacteriologic culture from the lower conjunctiva. Bacteriological samples were obtained without anesthesia to optimize bacterial growth 
by eliminating the bacterial growth inhibition associated with the preservatives found in anesthetics. The tip of the swab was inserted in the lower conjunctival fornix at the nasal margin and was passed once along the fornix between the nasal and temporal margins while rotating the swab. To reduce operator sampling bias, the same microbiology laboratory staff member, who was masked to randomization, collected all swab samples. Samples were dissolved in Hartmann's phosphate buffer with $1 \%$ sodium hexametaphosphate for 2 hours. Afterwards, $1 \mathrm{ml}$ of the solution was inoculated onto chocolate blood agar plates and was incubated for 48 hours at $37^{\circ} \mathrm{C}$ in $5 \%$ carbon dioxide incubator. Bacterial growth was evaluated in a quantitative manner as colony forming units (CFU) using the BBL Crystal Identification System method (Becton Dickinson and Company, Sparks, MD, USA) to count and record the number of CFU. The main outcome measure was the change in CFU between $t_{0}$ and $t_{1}$ samples, which was expressed as $\mathrm{CFU} / \mathrm{ml}$. Bacterial species were identified using standard biochemical and biophysical reactions.

\section{Preoperative and operative measures}

All standard preoperative preparation, such as cleaning of the eyelids, eyelashes, and the periocular skin with $10 \%$ povidone-iodine; draping of the eye; and instillation of a single drop of $5 \%$ povidone-iodine (without topical antibiotics) into the conjunctival sac, were performed in the operative theater 1 hour after collecting $\mathrm{t}_{1}$ culture samples. Standard cataract surgery procedure was performed by 4 experienced surgeons.

\section{Statistical analysis}

Student's t test was used for between-group comparison for numeric variables; Fisher's exact test was used when the total sample size was less than 30 . Pearson's chi-square was used for categorical outcomes, and Mann-Whitney $U$ was used for non-parametric significance. Statistical significance was set to $95 \%$ confidence level for all tests. The data were analyzed using Excel (Microsoft Inc., Redmond, WA, USA). The results were expressed as mean \pm standard deviation (SD).

\section{Results}

Sixty patients were enrolled, successfully completed the study, and had bilateral samples available for analysis. The mean age of patients was $63.6 \pm 15.9$ years (range, 28 to 90 years); 19 patients were male. There was no statistically significant difference between the 2 groups in age or gender. The 3-day group and the 1-hour group had 30 eyes each and the control group had 60 eyes.

Culture results at $t_{0}$ and $t_{1}$ are summarized in (Table 1 ). There was no statistically significant $(p=0.54)$ difference in the percent of culture-positive eyes between the 3-day group and the 1-hour group at baseline $\left(t_{0}\right)$; however, the 3 -day group had a significantly lower $(p=0.035)$ percent of culture-positive eyes at the end of treatment $\left(t_{1}\right)$.

The mean number of CFU on blood chocolate agar plates at $t_{0}$ was $56 \pm 139,39 \pm 103$, and $38.6 \pm 146$ for the no-treatment control group, the 3-day group, and

Table 1: Percent of eyes with positive culture at baseline $\left(t_{0}\right)$ and at the end of treatment schedule $\left(t_{1}\right)$.

\begin{tabular}{|l|l|l|l|l|l|}
\hline \multirow{2}{*}{ Time Point } & \multicolumn{3}{|l|}{ 3-Day Moxifloxacin $\mathbf{n}=\mathbf{3 0}$} & \multicolumn{1}{l|}{-Hour Moxifloxacin $\mathbf{n}=\mathbf{3 0}$} \\
\cline { 2 - 5 } & Ratio & \% eyes with positive culture & Ratio & \% eyes with positive culture & * $\mathbf{P}$ \\
\hline $\mathrm{t}_{0}$ & $7 / 10$ & $70 \%$ & $4 / 5$ & $80 \%$ & 0.54 \\
\hline $\mathrm{t}_{1}$ & $7 / 15$ & $46 \%$ & $11 / 15$ & $70 \%$ & 0.035 \\
\hline
\end{tabular}

"P value for between-group using Student's t test.

\section{\ Baseline (t0) $\mathrm{g}$ End of treatment (t1)}

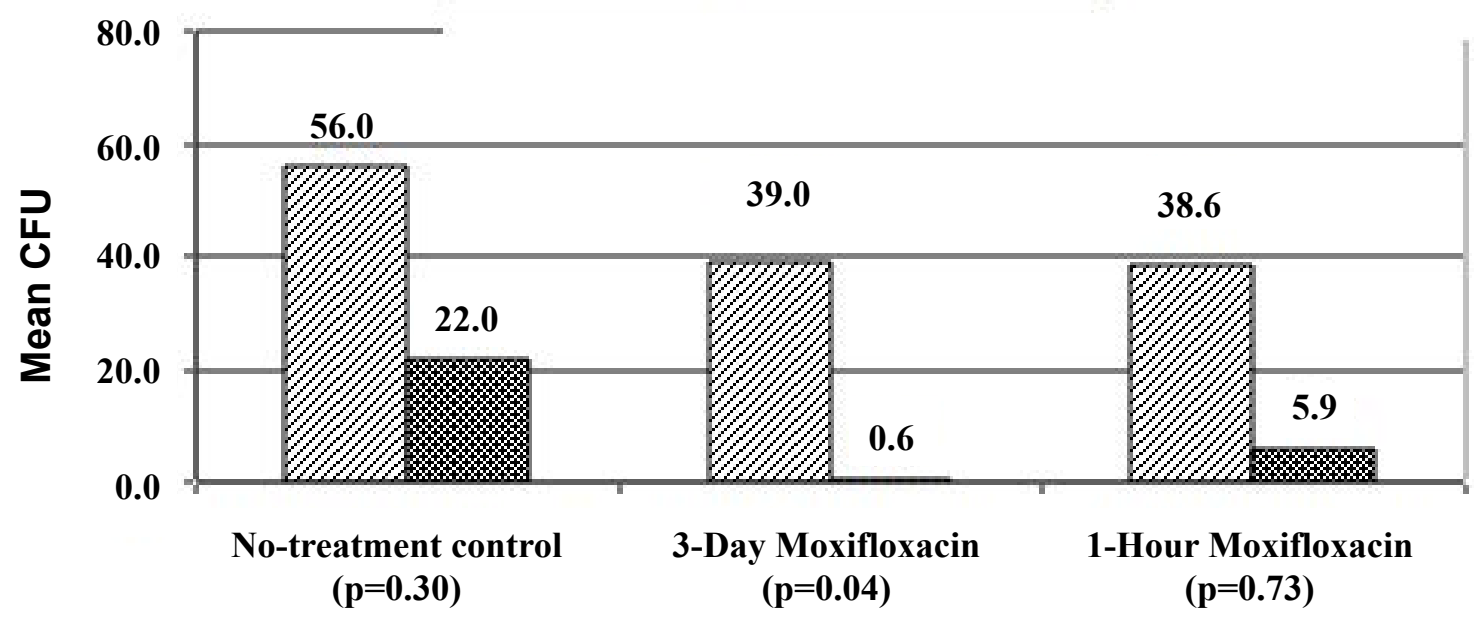

Figure 1: Mean number of colony forming units (CFU) of organisms cultured from swab samples at baseline $\left(t_{0}\right)$ and at the end of treatment schedule $\left(\mathrm{t}_{1}\right)$. 
the 1-hour group, respectively. At $\mathrm{t}_{1}$, the mean CFU was $22 \pm 98,0.6 \pm 0.7$, and $5.9 \pm 9$ for the no-treatment control, the 3-day group, and the 1-hour group, respectively. There were no statistically significant changes in the number of CFU between $t_{0}$ and $t_{1}$ in the no-treatment control $(p=0.30)$ and in the 1-hour group $(p=0.73)$; however, the difference was statistically significant in the 3 -day group $(p=0.04)$ (Figure 1 ).

There was no statistically significant difference in the percent of eyes with positive culture and the mean number of CFU of the most frequently isolated organisms from swab samples at baseline $\left(t_{0}\right)$ between the two treatment groups. However, at the end of treatment $\left(t_{1}\right)$, the percent of eyes with positive culture in the 3-day group and the 1-hour group was statistically significantly different in favor of the 3-day group ( $p$ $=0.019$ ), and the mean number of CFU for $S$. epidermidis from swab samples in the 3-day group and the 1-hour group was statistically significantly different in favor of the 3 -day group $(p=0.002)$. The most frequently cultured organisms from swab samples collected at baseline $\left(t_{0}\right)$ and at the end of the treatment schedule $\left(t_{1}\right)$ were $S$. epidermidis, Corynebacterium species, $S$. aureus, with $S$. epidermidis being the most frequently cultured organism overall at both time points. The prevalence of bacterial species in the 3-day group and the 1-hour group before and after moxifloxacin prophylactic treatment is shown in (Table 2 and Table 3).

None of the patients had an adverse reaction to moxifloxacin or the swabbing procedure. Likewise, none of the eyes developed endophthalmitis up to the last recorded follow-up visit at 6 months.

\section{Discussion}

The most common sources of bacteria that result in postoperative bacterial endophthalmitis are the eyelids and the ocular surface. Speaker, et al. [10] reported that an organism isolated from the vitreous was genetically indistinguishable from an isolate recovered from the patient's eyelid, conjunctiva, or nose in 14 out of $17(82 \%)$ cases of endophthalmitis. Because the incidence of postoperative endophthalmitis is exceedingly low, studies with thousands of patients are necessary to show differences in the effectiveness of one treatment group over another in reducing the risk of endophthalmitis. Therefore, the frequency of bacteria isolated from the ocular surface is used as an indicator of the risk of endophthalmitis $[15,20,21]$.

The decision to choose an antibiotic for prophylaxis can be difficult to make, as there are many antibiotics available in the market and many aspects by which the efficacy of an antibiotic is determined. However, in vitro studies help the decision-making process, as they provide information about the pharmacodynamics and minimum inhibitory concentration (MIC) of the antibiotic against ocular pathogens, and in vivo studies provide information regarding the safety and efficacy of the antibiotics in animals and humans. The fourth-generation fluoroquinolone moxifloxacin $0.5 \%$ was used in this study because of its broad-spectrum activity against Gram-positive and Gram-negative ocular pathogens, atypical microorganisms, and anaerobes [33,34]. Moxifloxacin is also a preservative-free formulation, which was an advantage because this feature eliminated preservative-associated bacterial growth inhibition, allowing for accurate analysis of data. Additionally, moxifloxacin is a safe and potent antibacterial agent, and did not negatively impact visual acuity, tear film breaks up time, or the integrity of corneal endothelial and epithelial cells [14,30-32,35]. Further, Hariprasad, et al. [34]. demonstrated that topical moxifloxacin is bioavailable and can achieve relatively high aqueous concentration,

Table 2: Percent of culture-positive eyes with the most frequently isolated organisms from swab samples at baseline $\left(\mathrm{t}_{0}\right)$ and at the end of treatment schedule $\left(t_{1}\right)$.

\begin{tabular}{|c|c|c|c|c|c|c|}
\hline \multirow[b]{2}{*}{ Organism } & \multicolumn{3}{|l|}{ Baseline $\left(\mathbf{t}_{0}\right)$} & \multicolumn{3}{|c|}{ End of treatment $\left(t_{1}\right)$} \\
\hline & $\begin{array}{l}\text { 3-Day Moxifloxacin } \\
n=30\end{array}$ & $\begin{array}{l}\text { 1-Hour } \\
\text { Moxifloxacin } \\
n=30\end{array}$ & ${ }^{*} \mathbf{P}$ & $\begin{array}{l}\text { 3-Day } \\
\text { Moxifloxacin } \\
n=30\end{array}$ & $\begin{array}{l}\text { 1-Hour } \\
\text { Moxifloxacin } \\
n=30\end{array}$ & ${ }^{*} \mathbf{P}$ \\
\hline Staphylococcus epidermidis & $60 \%$ & $76 \%$ & 0.170 & $37 \%$ & $70 \%$ & 0.019 \\
\hline Corynebacterium species & $23.0 \%$ & $87.0 \%$ & 0.233 & $0 \%$ & $3.0 \%$ & 1 \\
\hline Staphylococcus aureus & $17.0 \%$ & $27.0 \%$ & 0.424 & $10 \%$ & $23.0 \%$ & 0.299 \\
\hline
\end{tabular}

*Pearson chi-square; Fisher exact test.

Table 3: Mean number of colony forming units (CFU) of the most frequently isolated organisms from swab samples at baseline $\left(t_{0}\right)$ and at the end of treatment schedule $\left(t_{1}\right)$.

\begin{tabular}{|c|c|c|c|c|c|c|}
\hline \multirow[b]{2}{*}{ Organism } & \multicolumn{3}{|l|}{ Baseline $\left(\mathbf{t}_{0}\right)$} & \multicolumn{3}{|c|}{ End of treatment $\left(t_{1}\right)$} \\
\hline & $\begin{array}{l}\text { 3-Day } \\
\text { Moxifloxacin } \\
\text { Mean CFU (aSD) } \\
n=30\end{array}$ & $\begin{array}{l}\text { 1-Hour } \\
\text { Moxifloxacin } \\
\text { Mean CFU (SD) } \\
\mathrm{N}=30\end{array}$ & ${ }^{b} \boldsymbol{P}$ & $\begin{array}{l}\text { 3-Day } \\
\text { Moxifloxacin } \\
\text { Mean CFU (SD) } \\
n=30\end{array}$ & $\begin{array}{l}\text { 1-Hour } \\
\text { Moxifloxacin } \\
\text { Mean CFU (SD) } \\
n=30\end{array}$ & ${ }^{b} \boldsymbol{P}$ \\
\hline Staphylococcus epidermidis & $25(92.47)$ & $38.0(149.10)$ & 0.448 & $0.52(0.79)$ & $5(8.27)$ & 0.002 \\
\hline Corynebacterium species & $6(29.66)$ & $0.24(0.79)$ & 0.264 & 0 & $0.03(0.17)$ & 0.317 \\
\hline Staphylococcus aureus & $0.14(0.58)$ & $0.24(0.64)$ & 0.268 & $0.1(0.31)$ & $0.62(1.50)$ & 0.13 \\
\hline
\end{tabular}

$\mathrm{a}=$ Standard deviation; $\mathrm{b}=$ Mann-Whitney $\mathrm{U}$. 
and that, although the vitreous concentration was lower than that of the aqueous, the levels achieved would be adequate for prophylaxis, as the $\mathrm{MIC}_{50}$ was exceeded for many key bacterial pathogens. The landmark animal study with anterior chamber challenge by Kowalski, et al. [36] provided valuable evidence that topical moxifloxacin might be effective against bacterial endophthalmitis after cataract surgery. Among the moxifloxacin-treated eyes, all anterior and posterior chamber cultures were negative, and there was no clinical evidence of infections in eyes receiving moxifloxacin every 15 minutes for 1 hour ( 5 drops), followed by anterior chamber challenge, then 1 drop of moxifloxacin, and finally 4 more drops over the following 24 hours.

The current study evaluated the conjunctival flora and compared the effect of preoperative topical moxifloxacin prophylaxis begun 3 days before surgery (12 drops) with the administration of moxifloxacin for 1 hour before surgery (4 drops). There was a statistically significant difference in the mean number of CFU of the most frequently isolated organisms from swab samples at baseline $\left(t_{0}\right)$ and at the end of treatment schedule $\left(t_{1}\right)$ in favor of eyes treated with moxifloxacin for 3 days preoperatively versus 1 hour preoperatively. These results suggest that there is a greater bactericidal effect with 3 days of preoperative moxifloxacin relative to a 1-hour preoperative application. The high frequency of S. epidermidis isolated from the ocular swabs confirms the data of a similar study conducted by Vasavada, et al. [20]. Although a 3-day preoperative regimen of moxifloxacin significantly reduced the number of bacterial colonies, it did not eradicate bacteria from the ocular surface entirely. This emphasizes the importance of using moxifloxacin as an adjunct treatment to povidone-iodine preoperatively. No clinically evident epithelial or intraocular toxicity was noted with the topical application of moxifloxacin.

Previous studies have examined the effect of moxifloxacin application to the ocular surface before surgery as a prophylactic measure to guard against postoperative infection, especially endophthalmitis $[16,20,25,26,36]$. All studies supported the use of moxifloxacin as a prophylactic agent against postoperative infection; however, they differed on the appropriate dosing regimen and the length of time adequate for prophylaxis. Ta, et al. [16] demonstrated the prophylactic effectiveness of moxifloxacin when applied 1 days prior to surgery. Vasavada, et al. [20] reported that prophylaxis beginning on the day of surgery was as effective as beginning a day before surgery in reducing the number of CFU of conjunctival flora. Although the current study demonstrated the advantage of beginning moxifloxacin treatment 3 days before surgery versus on the day of surgery, in terms of the efficacy of killing normal bacterial flora, it is conceivable however that moxifloxacin can be effective as a prophylactic agent against postoperative endophthalmitis when administered 1 day and 1 hour or 1 hour before surgery because of its superior potency [30], penetrability [31], and bioavailability [34].

Only 60 eyes, 30 per group, were tested. More significant differences between the treatment groups may have been found with a larger patient population. Although the study was single-masked, with the laboratory staff member being the only one masked to randomization, this fact would not be expected to influence the results of this type of study.

\section{Conclusion}

This study demonstrates that 3-day preoperative regimen using $0.5 \%$ moxifloxacin ophthalmic solution was effective in reducing the conjunctival flora. These results are in agreement with earlier studies and differ from recent studies reporting that frequent administration of $0.5 \%$ moxifloxacin for preoperative prophylaxis was not required to maximize its beneficial effects.

\section{Acknowledgement}

This was an investigator-initiated study.

The authors thank Heba Costandy, MD, MS for medical writing and editing contributions.

\section{References}

1. Kattan HM, Flynn HW Jr, Pflugfelder SC, Robertson C, Forster RK (1991) Nosocomial endophthalmitis survey; current incidence of infection after intraocular surgery. Ophthalmology 98: 227-238.

2. Javitt JC, Vitale S, Canner JK, Street DA, Krakauer H, et al. (1991) National outcomes of cataract extraction; endophthalmitis following inpatient surgery. Arch Ophthalmol 109: 1085-1089.

3. Menikoff JA, Speaker MG, Marmor M, Raskin EM (1991) A case-control study of risk factors for postoperative endophthalmitis. Ophthalmology 98: 1761-1768.

4. Kresloff MS, Castellarin AA, Zarbin MA (1998) Endophthalmitis. Surv Ophthalmol 43: 193-224.

5. Montan PG, Koranyi G, Setterquist HE, Stridh A, Philipson BT, et al. (1998) Endophthalmitis after cataract surgery: risk factors relating to technique and events of the operation and patients history; a retrospective case-control study. Ophthalmology 105: 2171-2177.

6. Schmitz S, Dick HB, Krummenauer F, Pfeiffer N (1999) Endophthalmitis in cataract surgery: results of a German survey. Ophthalmology 106: 1869-1877.

7. Leaming DV (2004) Practice styles and preferences of ASCRS members--2003 survey. J Cataract Refract Surg 30: 892-900.

8. Taban M, Behrens A, Newcomb RL, Nobe MY, Saedi G, et al. (2005) Acute endophthalmitis following cataract surgery; a systematic review of the literature. Arch Ophthalmol 123: 613-620.

9. West ES, Behrens A, McDonnell PJ, Tielsch JM, Schein OD (2005) The incidence of endophthalmitis after cataract surgery among the U.S. Medicare population increased between 1994 and 2001. Ophthalmology 112: 1388-1394.

10. Speaker MG, Milch FA, Shah MK, Eisner W, Kreiswirth BN (1991) Role of external bacterial flora in the pathogenesis 
of acute postoperative endophthalmitis. Ophthalmology 98 639-649.

11. Arantes TE, Cavalcanti RF, Diniz Mde F, Severo MS, Lins Neto J, et al. (2006) Conjunctival bacterial flora and antibiotic resistance pattern in patients undergoing cataract surgery. Arq Bras Oftalmol. Enero-febrero 69: 33-36.

12. Gerkowicz M, Gruszecka-Gerkowicz R, Kosior-Jarecka E, Pietraś-Trzpiel M (2005) Changes in bacterial flora of conjunctival sac in patients prophylacticaly treated with antibiotic before cataract operation. Klin Oczna 107: 675-680.

13. Romero $P$, Méndez I, Salvat M, Fernández J, Almena M (2006) Intracameral cefazolin as prophylaxis against endophthalmitis in cataract surgery. J Cataract Refract Surg Marzo 32: 438-441.

14. Lane SS, Osher RH, Masket S, Belani S (2008) Evaluation of the safety of prophylactic intracameral moxifloxacin in cataract surgery. J Cataract Refract Surg 34: 1451-1459.

15. Maeck CR, Eckardt C, Höller C (1990) Preoperative disinfection of the conjunctiva with PVP-iodine. Fortschr Ophthalmol 87: 320-323

16. Ta CN, Chan I, Dhatt HS, Paterno J, Fisher E, et al. (2008) Prospective comparison of topical moxifloxacin in eliminating conjunctival bacterial flora following a one-day or onehour application. J Ocul Pharmacol Ther 24: 427-431.

17. Binder CA, Miño de Kaspar H, Klauss V, Kampik A (1999) Preoperative infection prophylaxis with $1 \%$ polyvidon-iodine solution based on the example of conjunctival staphylococci. Ophthalmologe 96: 663-667.

18. Apt L, Isenberg SJ, Yoshimori R, Chang A, Lam GC, et al. (1995) The effect of povidone-iodine solution applied at the conclusion of ophthalmic surgery. Am J Ophthalmol 119: 701-705.

19. Starr MB, Lally JM (1995) Antimicrobial prophylaxis for ophthalmic surgery. Surv Ophthalmol 39: 485-501.

20. Vasavada AR, Gajjar D, Raj SM, Vasavada V, Vasavada V (2008) Comparison of 2 moxifloxacin regimens for preoperative prophylaxis: Prospective randomized triple-masked trial. Part 2: Residual conjunctival flora. J Cataract Refract Surg 34: 1383-1388.

21. Ta CN, Egbert PR, Singh K, Shriver EM, Blumenkranz MS, et al. (2002) Prospective randomized comparison of 3-day versus 1-hour preoperative ofloxacin prophylaxis for cataract surgery. Ophthalmology 109: 2036-2040.

22. Bucci FA Jr, Amico LM, Evans RE (2008) Antimicrobial efficacy of prophylactic gatifloxacin $0.3 \%$ and moxifloxacin $0.5 \%$ in patients undergoing phacoemulsification surgery. Eye Contact Lens 34: 39-42.

23. Snyder-Perimutter LS, Katz HR, Melia M (2000) Effect of topical ciprofloxacin $0.3 \%$ and ofloxacin $0.3 \%$ on reduction of bacterial flora on the human conjunctiva. $\mathrm{J}$ Cataract $\mathrm{Re}-$ fract Surg 26: 1620-1625.

24. Katz HR, Masket S, Lane SS, Sall K, Orr SC, et al. (2005) Absorption of topical moxifloxacin ophthalmic solution into human aqueous humor. Cornea 24: 955-958.

25. Kim DH, Stark WJ, O'Brian TP, Dick JD (2005) Aqueous penetration and biological activity of moxifloxacin $0.5 \%$ ophthalmic solution and gatifloxacin $0.3 \%$ solution in cataract surgery patient. Ophthalmology 112: 1992-1996.

26. Solomon R, Donnenfeld ED, Perry HD, Snyder RW, Nedrud C, et al. (2005) Penetration of topically applied gatifloxacin $0.3 \%$, moxifloxacin $0.5 \%$, and ciprofloxacin $0.3 \%$ into the aqueous humor. Ophthalmology 112: 466-469.

27. Price MO, Quillin C, Price FW Jr (2005) Effect of gatifloxacin ophthalmic solution $0.3 \%$ on human corneal endothelial cell density and aqueous humor gatifloxacin concentration. Curr Eye Res 30: 563-567.

28. Ogawa GS, Hyndiuk RA (1993) The fluoroquinolones: new antibiotics in ophthalmology. Int Ophthalmol Clin 33: 59-68.

29. Drlica K (1999) Mechanism of fluoroquinolone action. Curr Opin Microbiol 2: 504-508.

30. Kowalski RP, Yates KA, Romanowski EG, Karenchak LM, Mah FS, et al. (2005) An ophthalmologist's guide to understanding antibiotic susceptibility and minimum inhibitory concentration data. Ophthalmology 112: 1987-1991.

31. Wagner RS, Abelson MB, Shapiro A, Torkildsen G (2005) Evaluation of moxifloxacin, ciprofloxacin, gatifloxacin, ofloxacin, and levofloxacin concentration in human conjunctival tissues. Arch Ophthalmol 123: 1282-1283.

32. Silver LH, Woodside AM, Montgomery DB (2005) Clinical safety of moxifloxacin ophthalmic solution $0.5 \%$ (Vigamox () in pediatric and nonpediatric patients with bacterial conjunctivitis. Surv Ophthalmol 50: 55-63.

33. Mather R, Karenchak LM, Romanowski EG, Kowalski RP (2002) Fourth generation fluoroquinolones: new weapons in the arsenal of ophthalmic antibiotics. Am J Ophthalmol 133: $463-466$.

34. Hariprasad SM, Blinder KJ, Shah GK, Apte RS, Rosenblatt B, et al. (2005) Penetration pharmacokinetics of topically administered $0.5 \%$ moxifloxacin ophthalmic solution in human aqueous and vitreous. Arch Ophthalmol 123: 39-44.

35. Donaldson KE, Marangon FB, Schatz L, Venkatraman AS, Alfonso EC (2006) The effect of moxifloxacin on the normal human cornea. Curr Med Res Opin 22: 2073-2080.

36. Kowalski RP, Romanowski EG, Mah FS, Yates KA, Gordon YJ (2004) Topical prophylaxis with moxifloxacin prevents endophthalmitis in a rabbit model. Am J Ophthalmol 138: 33-37. 